\title{
Growth of Highly-Oriented Carbon Nanotubes by Plasma-Enhanced Hot Filament Chemical Vapor Deposition
}

\author{
Z. P. Huang, J. W. Xu, Z. F. Ren", and J. H. Wang \\ Materials Synthesis Laboratory \\ Departments of Physics and Chemistry, and \\ Center for Advanced Photonic and Electronic Materials (CAPEM), \\ State University of New York at Buffalo, Buffalo, NY 14260 \\ M. P. Siegal and P. N. Provencio \\ Sandia National Laboratories, Albuquerque, NM 87185-1421
}

\begin{abstract}
Highly-oriented, multi-walled carbon nanotubes were grown on polished polycrystalline and single crystal nickel substrates by plasma enhanced hot filament chemical vapor deposition at temperatures below $666^{\circ} \mathrm{C}$. The carbon nanotubes range from 10 to $500 \mathrm{~nm}$ in diameter and 0.1 to $50 \mu \mathrm{m}$ in length depending on growth conditions. Acetylene is used as the carbon source for the growth of the carbon nanotubes and ammonia is used for dilution gas and catalysis. The plasma intensity, acetylene to ammonia gas ratio and their flow rates, etc. affect the diameters and uniformity of the carbon nanotubes.
\end{abstract}

* email: zren@acsu.buffalo.edu 


\section{DISCLAIMER}

This report was prepared as an account of work sponsored by an agency of the United States Government. Neither the United States Government nor any agency thereof, nor any of their employees, make any warranty, express or implied, or assumes any legal liability or responsibility for the accuracy, completeness, or usefulness of any information, apparatus, product, or process disclosed, or represents that its use would not infringe privately owned rights. Reference herein to any specific commercial product, process, or service by trade name, trademark, manufacturer, or otherwise does not necessarily constitute or imply its endorsement, recommendation, or favoring by the United States Government or any agency thereof. The views and opinions of authors expressed herein do not necessarily state or reflect those of the United States Government or any agency thereof. 


\section{DISCLAIMER}

Portions of this document may be illegible in electronic image products. Images are produced from the best available original document. 
Following the first reported observation of carbon nanotubes [1], numerous papers have reported studies on the yield of carbon nanotubes, their diameter and wall thickness [2-6], growth mechanisms [2,7,8], alignment [6,9], electron emission properties [10-14], nanodevices [15], theoretical predictions [2], and potential applications [2]. Nanotube alignment is particularly important to enable both fundamental studies and applications, such as flat panel displays, vacuum microelectronics, chargeable batteries, etc. However, only one report exists on the growth of aligned carbon nanotubes by thermal decomposition of acetylene in nitrogen gas at temperature above $700^{\circ} \mathrm{C}$ on mesoporous silica containing iron nanoparticles [6] before our report on growth of large arrays of well-aligned carbon nanotubes on glass [16]. Here we report the growth of highly-oriented, multi-walled carbon nanotubes on nickel substrates at low temperatures by the same method (plasma enhanced hot tungsten-filament chemical vapor deposition) described in our previous paper [16]. The motivation to grow carbon nanotubes on $\mathrm{Ni}$ substrates is for the applications of using carbon nanotubes as battery electrodes and energy storage. We use acetylene $\left(\mathrm{C}_{2} \mathrm{H}_{2}\right)$ to provide carbon for the growth of the carbon nanotubes and ammonia $\left(\mathrm{NH}_{3}\right)$ gas for both dilution gas and catalysis. The catalytic role of ammonia is discussed in our previous paper [16].

The base pressure of the deposition chamber is $<6 \times 10^{-6}$ Torr. We grew carbon nanotube films in a pressure of $1-20$ Torr maintained by flowing acetylene and ammonia gases with a total flow rate of $120-200 \mathrm{sccm}$. We varied the acetylene-to-ammonia volume ratio from 1: 2 to 1:10 for different experimental runs. Both polished polycrystalline and single-crystal $\mathrm{Ni}$ substrates were used. After stabilizing the working pressure, the tungsten filament coil powered by a DC source and the plasma-generator were turned on to generate heat and plasma. Under the present experimental set-up, the temperature of samples is estimated to be below $666^{\circ} \mathrm{C}$ (which is the strain point of the display glass provided by Corning Inc.) since the display glass sit side by side with the $\mathrm{Ni}$ did not show any noticeable deformation after the experiments [16] and also $\mathrm{Ni}$ is not red-hot by visual observation. Growth durations were from $10 \mathrm{~min}$ to $5 \mathrm{~h}$ depending on the desired carbon nanotube lengths. Samples were examined by scanning electron microscopy (SEM, Hitachi S-4000) to measure tube lengths, diameters, site distributions, alignment, density and uniformity. High-resolution transmission electron microscopy (TEM) was used to determine 
the microstructure of individual tubes. Samples were also examined by $\mathrm{x}$-ray diffraction, Raman spectroscopy, and $\mathrm{x}$-ray photoemission spectroscopy to study the structure, crystallinity, composition, and central core and tube wall structures.

Figure 1(a) is an SEM micrograph showing the alignment of carbon nanotubes grown on polycrystalline Ni. Growth conditions are described in Table 1(a). Clearly, the carbon nanotubes are oriented perpendicular to the substrate surface and are quite uniform in height. Note that the carbon nanotubes do not grow well along the $\mathrm{Ni}$ grain boundaries, shown by the two empty tracks running from upper left and from upper right down to bottom, which is due to the fact that grain boundaries do not have enough $\mathrm{Ni}$ as catalysis. Fig. 1(b) is a higher magnification image of an area within a single $\mathrm{Ni}$ grain and clearly shows that the distribution uniformity within these grains is reasonably good. However, there exists a wide distribution of carbon nanotube diameters ranging from $60-500 \mathrm{~nm}$. Fortunately, the uniformity in both diameter and site distributions can be controlled via the growth conditions.

Figure 2 is an SEM micrograph showing carbon nanotubes grown on polycrystalline $\mathrm{Ni}$ under a different condition as described in Table 1(b). The tube diameter is smaller and its distribution is narrower, ranging from 200 to $300 \mathrm{~nm}$. This difference results mainly from increasing the plasma intensity. The increase of plasma intensity apparently reduced the catalytic Ni particle size. Smaller Ni particles result thinner carbon nanotubes. Based on this observation, we further increased the plasma intensity in an ensuing experiment. The growth conditions are listed in Table 1(c). In order to keep the substrates at low temperature, the filament current was reduced from the usual 9 to 6 amperes. Figure 3 is an SEM micrograph showing the carbon nanotubes grown under these conditions. This further increase in plasma intensity results in two structural changes. First, there is a substantial decrease in the average tube diameters from $\sim 250$ $\mathrm{nm}$ as shown in Fig. 2 to $\sim 100 \mathrm{~nm}$ as shown in Fig. 3. Second, the tube lengths increase dramatically. This high growth rate is very attractive for the potential large-scale production of carbon nanotubes with long lengths. Finally, we note that when the diameters are $<20 \mathrm{~nm}$, the tubes are less straight than for those with diameters $>50 \mathrm{~nm}$ [16]. The good alignment of carbon 
nanotubes on glass [16] and silicon [17] will be very important to the development of coldcathode electron emitters for applications such as flat panel displays, microelectronics, etc.

Finally, we performed TEM analysis on the carbon nanotubes to determine whether or not these film structures are truly carbon nanotubes, as opposed to carbon fiber-like structures. Samples with carbon nanotubes grown to several microns in length were easily scraped off a nickel substrate directly onto a copper TEM grid for analysis. Fig. 4 shows a typical image obtained for these carbon nanotubes. The disorder is due entirely to the random process of nanotube collection on the TEM grid. The dark spot at the end of each structure is a small ball of $\mathrm{Ni}$ that appears to cap each tube. This image is typical to those reported elsewhere demonstrating carbon nanotube structure [2,3]. Nevertheless, the insert to fig. 4 , a high-resolution image of a portion of a typical carbon nanotube structure, is more convincing. The width of this tube is $\sim 30$ $\mathrm{nm}$ and represents a highly defected multi-walled structure with a hollow center. The fringes on each side of the tube identify individual cylindrical graphitic layers. This particular carbon nanotube is a structure with approximately 15 walls of graphitized carbon. Both the angular bend in the structure and the appearance of carbon walls running across the diameter of the nanotube demonstrate structural defects suggestive of twisting of the nanotube structure. The lack of fringes inside the nanotube, as well as the lighter contrast compared to the nanotube walls, indicates that the core of the structure is hollow.

In summary, we synthesized large-area highly-oriented carbon nanotubes at temperatures below $666^{\circ} \mathrm{C}$ by plasma-enhanced hot filament chemical vapor deposition. Acetylene gas is used to provide carbon for nanotube growth and ammonia gas is used for dilution and catalysis [16]. Plasma intensity is critical in determining the nanotube aspect ratios (diameter and length), and range of both site and height distributions within a given film.

\section{Acknowledgements:}

This material is based upon work supported in part by the U. S. Army Research Office under grant number DAAG55-97-1-0139. The management of Dr. Robert R. Reeber to this 
program is greatly appreciated. The authors would also like to thank Mr. G. Sagerman for his technical support and Mr. P. Bush for his insightful discussions and valuable help in SEM studies. High-resolution transmission electron microscopy (TEM) was performed on a JEOL 2010 at The University of New Mexico, using phase contrast digital imaging with a CCD slow scan camera. Sandia is a multiprogram laboratory operated by Sandia Corporation, a Lockheed Martin Company, for the U.S. DOE under Contract No. DE-AC04-94AL85000. 


\section{References:}

1. S. Iijima, Nature 354,56 (1991).

2. T. W. Ebbesen, Book, "CARBON NANOTUBES: Preparation and Properties" by CRC Press, Inc., Boca Raton, Florida (1997).

3. A. Thess, R. Lee, P. Nikolaev. H. Dai, P. Petit, J. Robert, C. Xu, Y. Lee, S. Kim, A. Rinzler, D. Colbert, G. Scuseria, D. Tomanek, J. Fischer, and R. Smalley, Science 273, 483 (1996).

4. C. Journet, W. K. Maser, P. Bernier, A. Loiseau, M. Lamy de la Chapelle, S. Lefrant, P. Deniard, R. Lee, and J. E. Fischer, Nature 388, 756 (1997).

5. A. A. Setlur, J. M. Lauerhaas, J. Y. Dai, and R. H. Chang, Appl. Phys. Lett. 69, 345 (1996).

6. W. Z. Li, S. S. Xie, L. X. Qian, B. H. Chang, B. S. Zou, W. Y. Zhou, R. A. Zhao, and G. Wang, Science 274, 1701 (1996).

7. J. C. Charlier, A. De Vita, X. Blasé, and R. Car, Science 275, 646 (1997).

8. M. Yudasaka, R. Kikuchi, Y. Ohki, E. Ota, and S. Yoshimura, Appl. Phys. Lett. 70, 1817 (1997).

9. P. M. Ajayan, O. Stephan, C. Colliex, and D. Trauth, Science 265, 1212 (1994).

10. P. G. Collins and A. Zettl, Phys. Rev. B 55, 9391 (1997).

11. H. Schmid and H. W. Fink, Appl. Phys. Lett. 70, 2679 (1997).

12. P. G. Collins and A. Zettl, Appl. Phys. Lett. 69, 1969 (1996).

13. A. G. Rinzler, J. H. Hafner, P. Nikolaev, L. Lou, S. G. Kim, D. Tomanek, P. Nordlander, D. Colbert, and R. E. Smalley, Science 269, 1550 (1995).

14. W. A. de Heer, A. Chatelain, and D, Ugarte, Science 270, 1179 (1995).

15. P. G. Collins, A. Zettl, H. Bando, A. Thess, and R. E. Smalley, Science 278, 100 (1997).

16. Z. F. Ren, Z. P. Huang, J. W. Xu, J. H. Wang, P. Bush, M. P. Siegal, and P. N. Provencio, Science (in press).

17. J. W. Xu, Z. P. Huang, Z. F. Ren, J. H. Wang, M. P. Siegal, and P. N. Provencio, unpublished results. 
Table 1. Growth conditions for the nanotube films shown in Figs. 1(a) and 1(b), Fig. 2, and Fig. 3

$\begin{array}{llll}\mathrm{C}_{2} \mathrm{H}_{2} / \mathrm{NH}_{3} & \text { Filament Current } & \text { Plasma Intensity } & \text { Growth Time } \\ (\mathrm{sccm} / \mathrm{sccm}) & \text { (amperage, } \mathrm{A}) & \text { (amperage / voltage / watts) } & \text { (minutes) }\end{array}$

(a): For Figs. 1(a) and 1(b)

$\begin{array}{llll}20 / 100 & 9 & 0.09 / 460 / 50 & 90\end{array}$

(b): For Fig. 2

$80 / 160$

9

$0.2 / 640 / 140$

25

(c): For Fig. 3

$40 / 80$

6

$0.3 / 700 / 220$

20 


\section{Figure Captions}

Fig.1. (a) SEM micrograph shows alignment of carbon nanotubes grown on a large-area of polycrystalline Ni substrates. Note that the carbon nanotubes grow well inside each grain, but not along the grain boundaries. (b) A magnified view of 1(a) to show the diameter size and distribution, height uniformity, density, etc. The tube diameters range from $\sim 60$ to $500 \mathrm{~nm}$. The density is about $10^{6}$ nanotubes $/ \mathrm{mm}^{2}$.

Fig. 2. SEM micrograph of carbon nanotubes grown at a higher plasma intensity under the conditions listed in Table 1(b). The diameter uniformity is substantially narrowed and the average diameter size is reduced. Most of the tube diameters are $\sim 250 \mathrm{~nm}$. The density increased to $4 \times 10^{6}$ nanotube $/ \mathrm{mm}^{2}$, about 4 times higher than that shown in Fig. 1 .

Fig. 3. SEM micrograph shows that carbon nanotubes with higher aspect ratios are synthesized using a higher plasma intensity than that used for the samples in Fig. 2 . The length of the carbon nanotubes is at least $10 \mu \mathrm{m}$ and the diameters are $<100 \mathrm{~nm}$.

Fig. 4. TEM micrograph shows a cluster of carbon nanotubes scraped off a Ni substrate directly onto a $\mathrm{Cu}$ TEM grid. The insert is a high-resolution TEM cross-section image from a portion of a single multi-walled carbon nanotube structure. 

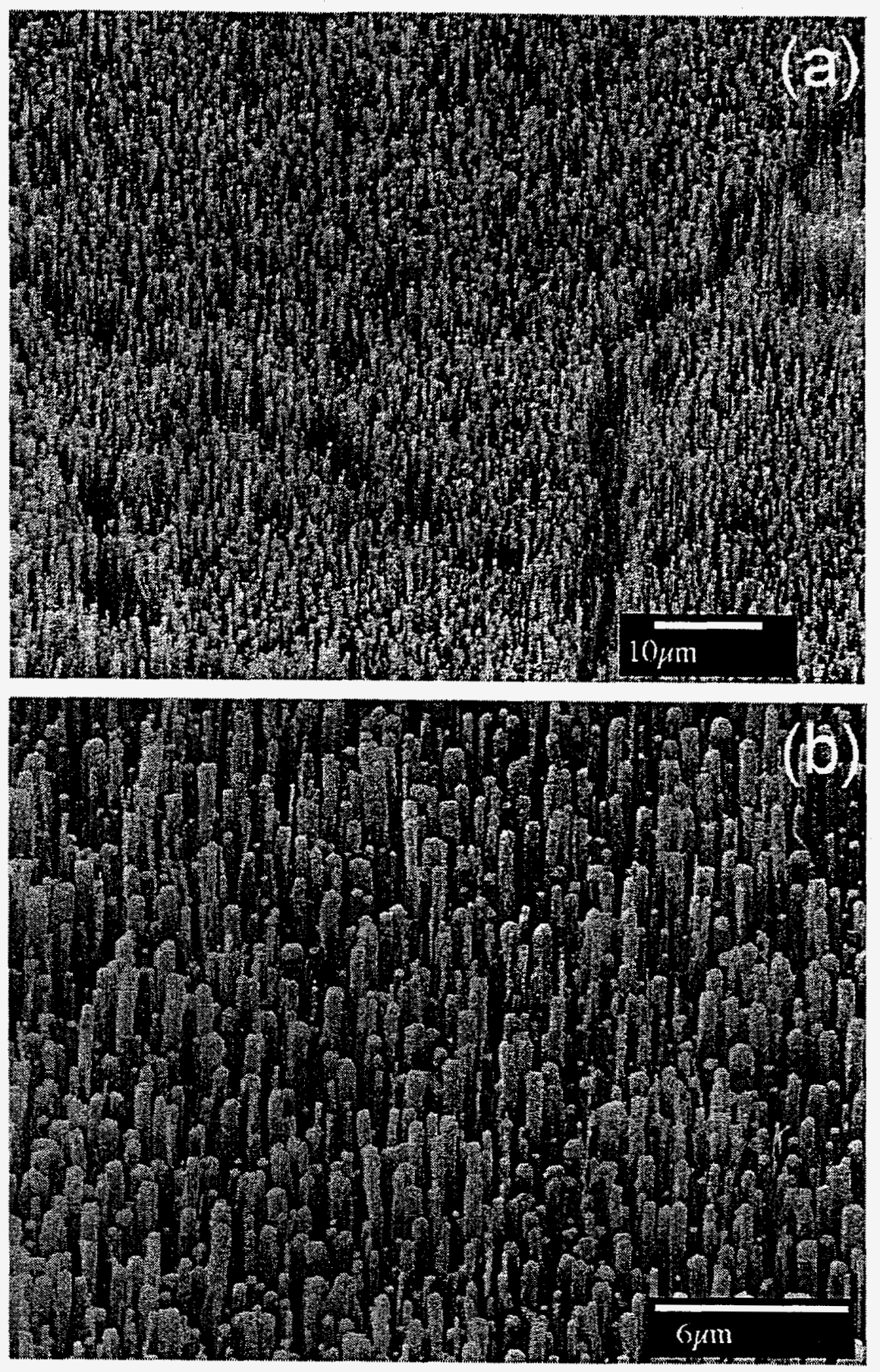

Fig. 1

Huang, et al. 


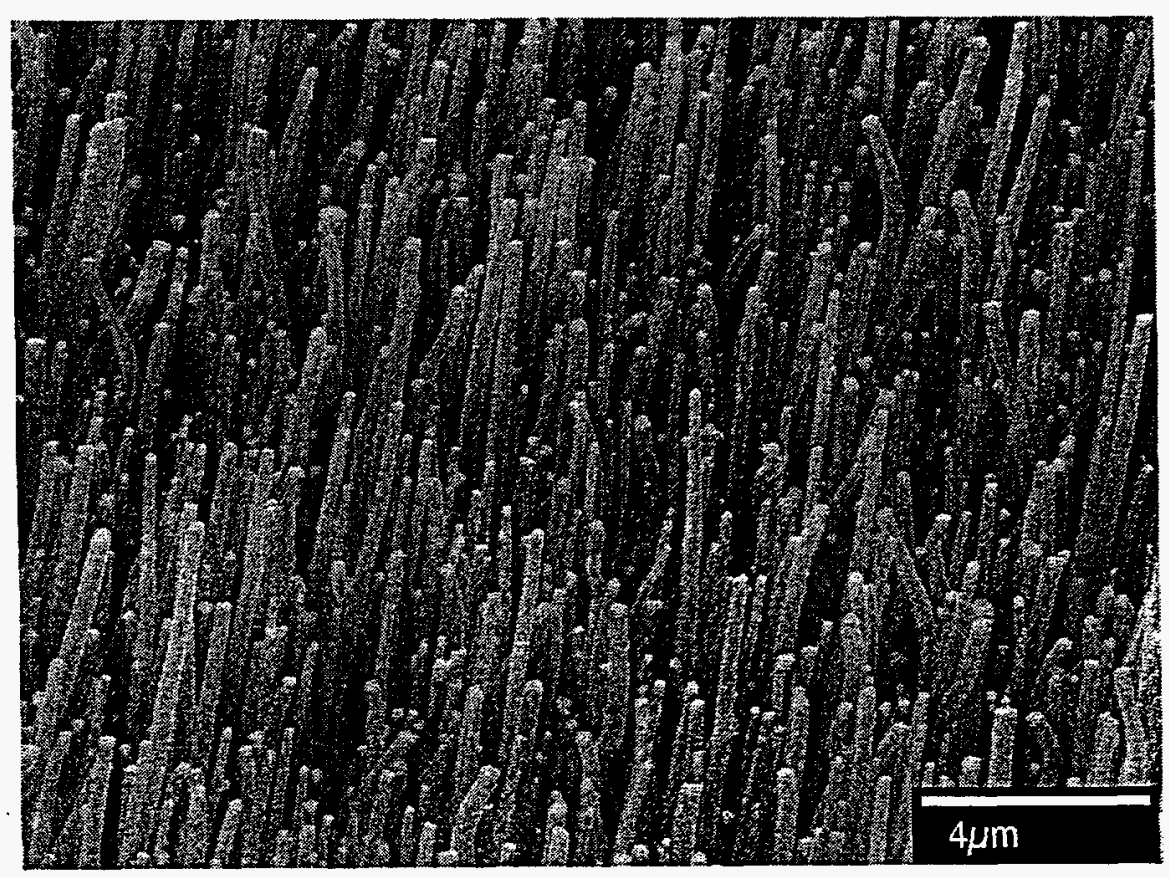

Fig. 2

Huang, et al. 


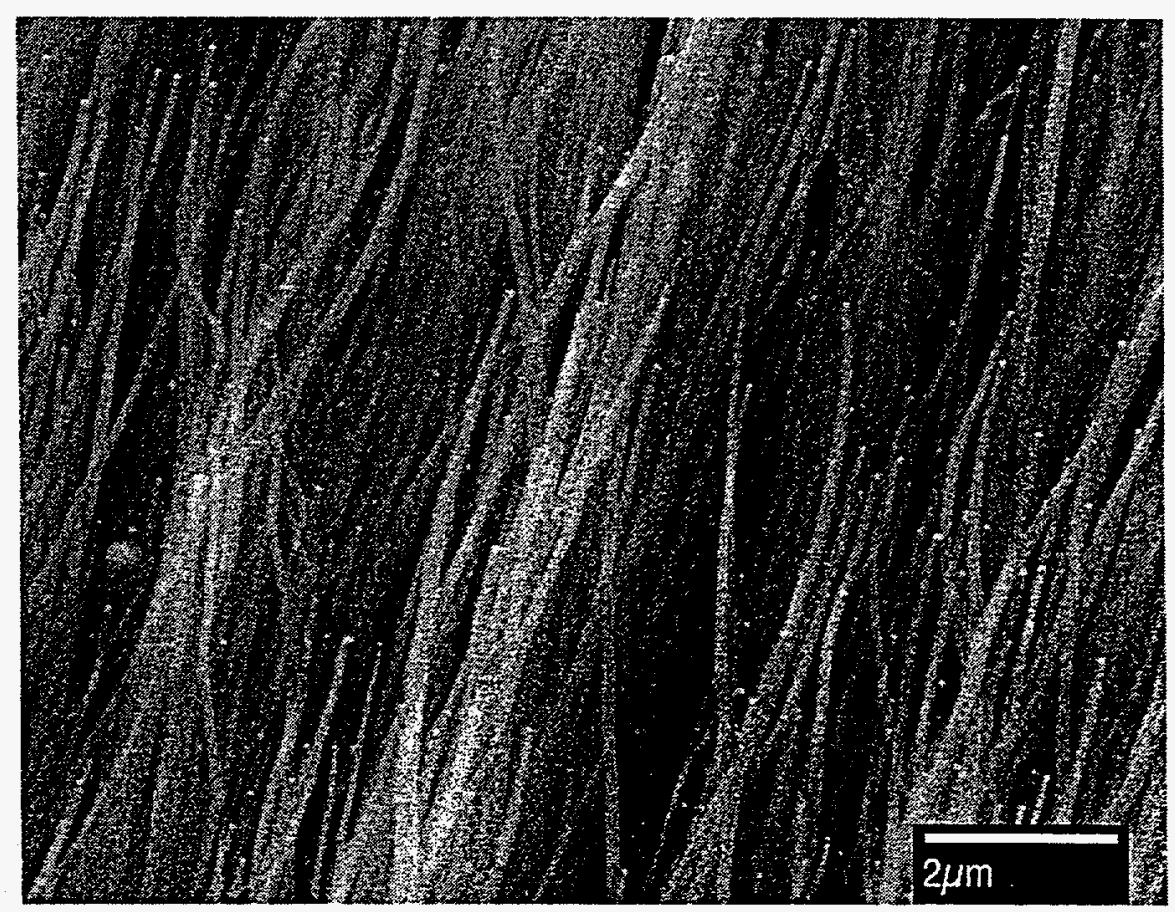

Fig. 3

Huang, et al. 


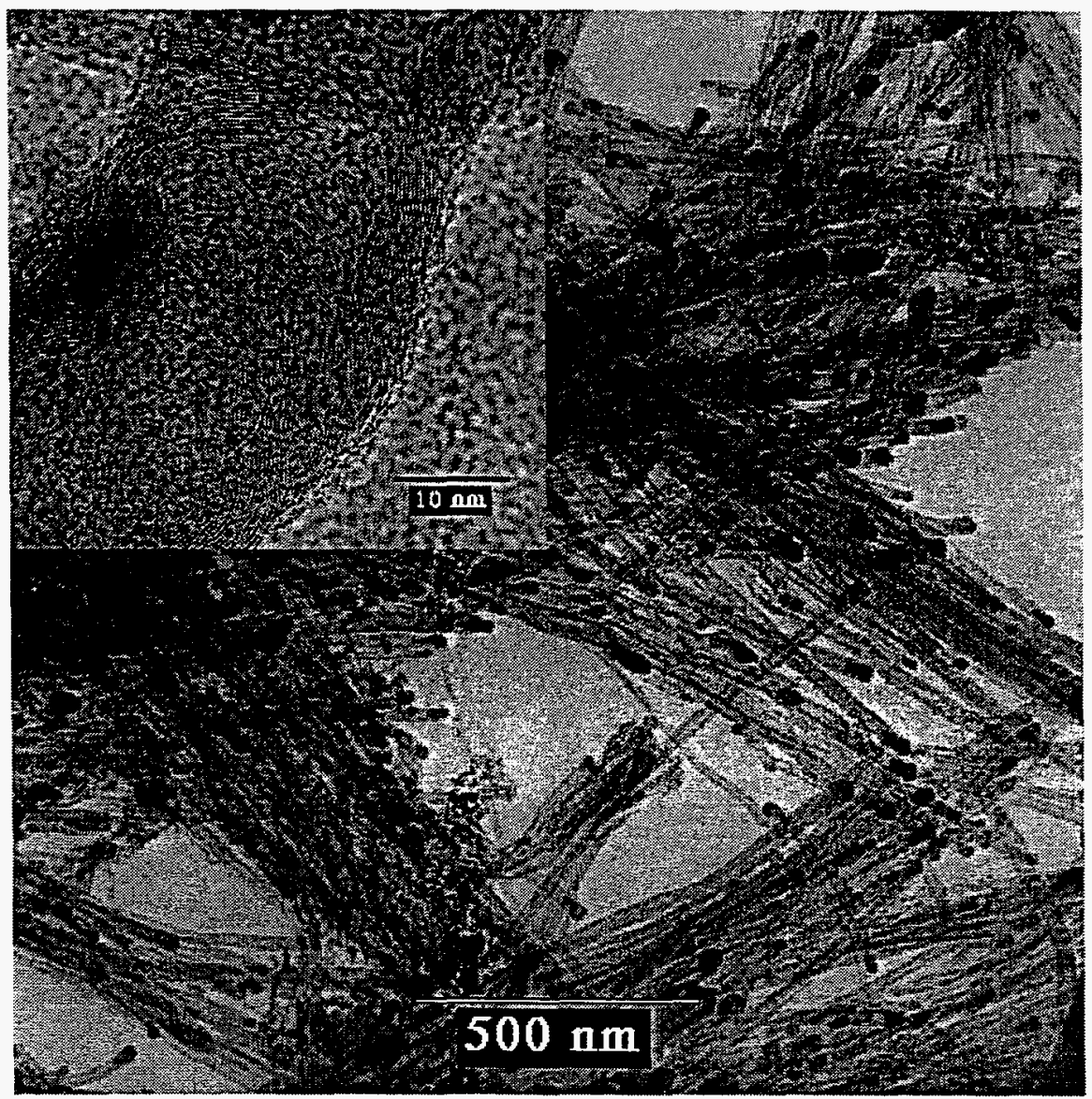

Fig. 4

Huang, et al. 